\title{
A incerta viagem dos mitos e das mulheres que neles vivem: a reinvenção de Helena
}

\section{Jorge Deserto \\ Universidade do Porto}

Resumo: Os antigos Gregos assentaram grande parte da sua identidade - e da sua cultura, e da sua literatura num conjunto de narrativas, variadas, multiformes, capazes de incluir toda a experiência humana. A essas narrativas costumamos chamar mitos. É sobre elas que assenta a força e a variedade da literatura grega, de Homero à tragédia, dos poetas líricos aos historiadores e aos filósofos. Eram narrativas de uma incrível plasticidade, permanentemente contadas e recontadas, sempre prontas a assumirem novas formas e diferentes versões, num incessante diálogo consigo mesmas. Neste texto, abordo esta capacidade de reinvenção a propósito da figura de Helena (em Homero, em Estesícoro, em Eurípides, em Heródoto), talvez aquela, de entre as figuras mitológicas, que mais viu refeita a sua história. Se hoje continuamos a reescrever os mitos gregos, talvez isso aconteça porque os próprios Gregos já entendiam que essa era a forma indicada de lidar com eles: reinventá-los continuamente.

Palavras-chave: Mitologia, Grécia antiga, Literatura Grega, Helena de Troia

\begin{abstract}
Ancient Greeks based much of their identity - and of their culture, and of their literature - on a set of narratives, varied, multiform, able to include all human experience. To these narratives we usually call myths. It is on them that relies the strength and variety of Greek literature, from Homer to the tragedy, from the lyric poets to the historians and the philosophers. These were stories of incredible plasticity, constantly told and retold, always ready to take on new forms and different versions, in a constant dialogue with


Jorge Deserto

themselves. In this paper, I deal with this reinvention capacity, taking as example the figure of Helen (in Homer, in Stesichorus, in Euripides, in Herodotus), perhaps the one, from all the mythological characters, which saw her history written in more different ways. If today we continue to write and rewrite the Greek myths, this may happen perhaps because the Greeks themselves understood that was the right way of dealing with them, to reinvent them continuously.

Keywords: Mythology, Ancient Greece, Greek Literature, Helen of Troy

1.

A antiga Grécia firmava parte substancial da sua identidade - o que significa, também, da sua cultura, da sua literatura - num conjunto de narrativas variadas, multiformes, capazes de incluir toda a experiência humana. A essas narrativas costumamos chamar mitos.

Estes mythoi rodeavam e embebiam toda a vida dos Gregos. Começavam a conviver com eles nos relatos das mães e das amas, e com eles enchiam a infância de viagens e batalhas, monstros e tempestades, deuses e heróis. ${ }^{1}$ Aprendiam a ler com eles. Ouviam-nos e partilhavam-nos em grandes cerimónias públicas e sentiam aqueles enredos como forma de cidadania e pertença. Viam-nos nos vasos e nos templos, nas estátuas e nas pinturas. Assistiam a eles em rituais, celebrações religiosas, procissões. Não havia situação da vida de que estivessem ausentes.

Compreende-se, por isso, por esta multiplicidade de faces, por esta presença que se confunde com o ritmo e a respiração da vida, que este fenómeno se torne particularmente avesso a tentativas de definição - e muitas têm sido propostas - e seja sujeito a tantos esforços de enquadramento e iluminação quantas as épocas, as modas e as teorias que em cada ocasião mais brilham. Há, como se compreende, uma infindável bibliografia sobre o tema, de que destaco, excluindo outras tão ou mais importantes, autores como Jean-Pierre Vernant (1965), Walter Burkert (1991), Marcel Detienne (1992), Victor Jabouille (1993; 1994), Richard Buxton (2000), Barry Powell (2002) ou Eric Csapo (2005).

Não é esta a ocasião para entrar longamente pela vereda estreita das definições. 
Definir é uma forma de enquadrar com rigor, mas também de emparedar. Quando lidamos com um tema que nos escapa por entre os dedos, as definições podem ser boias a que nos agarremos, mas também podem expor cruamente as suas limitações e o modo como o objeto do nosso estudo teima em fugir-nos. Não deixo, no entanto, de citar duas definições propostas por dois dos especialistas já mencionados, que tentam reconduzir a noção de mito ao seu patamar original, despindo-a de muitas das elaborações de teorias posteriores. Assim, afirma Richard Buxton (2000: 28), numa tentativa de definição muito devedora de Walter Burkert, ${ }^{2}$ como o próprio Buxton reconhece:

Mito grego é narrativa dos feitos de deuses e heróis e das suas relações com os mortais comuns, transmitida como uma tradição dentro do mundo grego antigo e de importância coletiva para um grupo ou grupos sociais específicos.

Pelo seu lado, Eric Csapo (2005: 9) propõe a seguinte definição:

Mito é uma narrativa que é considerada socialmente importante e que é contada de tal forma que permite a um coletivo social, no seu conjunto, partilhar a consciência dessa importância.

Qualquer uma destas definições teria aqui matéria para extensas considerações. Mas, de facto, não é a mitologia, na sua aceção de ciência que estuda os mitos, que aqui me interessa agora. Vou prender-me apenas a um dos pontos que as duas definições partilham, aquele que considera que os mitos são, antes de qualquer outra coisa, narrativas. Ora a narrativa é uma das matérias primas da literatura. 0 que me interessa sublinhar, antes de mais, é que o mito é o combustível central da literatura grega, toda ela, de Homero ao teatro, passando pela lírica e até pela historiografia ou pela obra dos filósofos. E porque isso também se cruza com as definições que acabámos de ler, convém dar conta de que, na esmagadora maioria das suas manifestações, a literatura grega é feita para circular no espaço público, para ser declamada ou representada diante da cidade reunida em grandes celebrações públicas ou, noutros casos, para circular no espaço mais restrito, mas significativo e influente, do symposion. ${ }^{3}$ Os mitos dão forma à literatura dos Gregos, tal como 
esta dá forma aos mitos. Juntos, como uma realidade que é impossível separar, são a base identitária de um povo habituado a definir-se, também, a partir destas histórias.

Hoje vemos - e encaramos isso como natural - os grandes mitos gregos a serem permanentemente recriados, nas mais variadas linguagens, com as mais diversas influências - e parece-nos absolutamente normal que a arte, em todas as suas formas, estabeleça um permanente diálogo com o seu passado, replicando-o, renovando-o, problematizando-o, por vezes das formas mais inesperadas ${ }^{4}$. Mas, mais do que uma novidade, estamos diante de um efeito de continuidade. A verdade é que isto já sucedia entre os Gregos, as narrativas que circulavam no espaço helénico comportavam-se como organismos vivos, de uma extrema plasticidade, sujeitas a uma incessante recriação e reinvenção. Embora também possa afirmar-se que os mitos constituíam a matriz religiosa que enquadrava a vida na Hélade, nada neles assume a feição de texto sagrado, imutável que encontramos em outras vivências religiosas do ocidente. Todos aqueles enredos podiam ser refeitos, retomados, e cada versão, embora sustentada nas anteriores, podia apontar outros caminhos, num permanente avolumar de camadas e leituras. Quer isto dizer que os mitos dos Gregos, desde a sua origem, nos incitam a desafiá-los, a fazer de novo. Os próprios Gregos, principalmente os do final do século $\mathrm{V}$ a.C., no momento mais poderoso do teatro ateniense, quase poderiam fazer suas, com uma ligeira alteração, as famosas palavras de Almada, na Invenção do dia claro:

Nós não somos do século de inventar as narrativas. As narrativas já foram inventadas. Nós somos do século de inventar outra vez as narrativas que já foram inventadas.

Este facto de, já na sua origem grega, se constituírem como um universo em permanente expansão é uma manifestação de força e uma das razões da sua constante presença ao longo da tradição literária e no mundo contemporâneo. No fundo, este movimento de constante reapropriação nada mais faz do que dar continuidade a algo que já está presente, com particular nitidez, na matriz da mitologia grega. 


\section{2.}

Em todo este universo, vasto e efervescente, um dos elementos mais perturbadores é seguramente a forma como nos mitos gregos aparecem as mulheres. Sabemos que a literatura grega é uma quase exclusiva sucessão de vozes masculinas - figuras como Safo, acima de tudo, ou Corina são as exceções que confirmam a regra - e, nessa medida, as narrativas míticas são um extenso catálogo dos medos e das ansiedades dos homens em relação a um território que lhes parece estranho e indecifrável. Mas o papel e a relevância das mulheres nas narrativas míticas ultrapassa claramente o lugar estreito e limitado que lhes estava reservado em termos sociais. É certo que, na maioria dos casos, as mulheres não deixam de ser vistas como mães, filhas, esposas ou irmãs, afinal o papel que lhes cabe no tecido social.5 Mas, as mais das vezes, os mitos subvertem esses papeis e colocam-nas em situações de rutura, nas quais a construção social é ameaçada e a estabilidade do mundo masculino é colocada em questão. É isso que faz a força e apelo de figuras como Clitemnestra ou Medeia, Fedra ou Antígona, qualquer delas merecedora de extensa análise, quer quanto ao seu lugar na literatura e na cultura gregas, quer quanto às questões que a sua receção levanta, quando filtrada por um olhar contemporâneo.

eja-me, no entanto, permitido avançar numa direção ligeiramente distinta e trazer a este texto o caso de Helena. Helena de Esparta e Helena de Troia. ${ }^{6}$ Esta dualidade é, desde logo a primeira marca. A mulher que arrastou atrás de si mil navios, aquela que, na Ilíada, chama 'marido' a dois homens (Menelau e Páris), aquela que é conhecida pela sua extrema beleza, é o mais próximo que os Gregos chegam de uma femme fatale. Refiro-me àquele tipo de figuras, muito presentes, por exemplo, numa certa época da tradição cinematográfica de Hollywood, que juntam a uma enorme beleza uma nítida consciência do poder que essa beleza e o seu efeito transportam consigo. 0 exemplo que me ocorre, e que eventualmente dirá mais sobre mim do que sobre a questão que estamos a tratar, é a figura de Laureen Bacall, no filme de 1944 To Have and Have Not, de Howard Hawks, quando se dirige a Humphrey Bogart dizendo:

You know how to whistle, don't you, Steve? You just put your lips together and... blow. 
Humphrey Bogart, é sabido, nunca mais foi o mesmo.

Helena de Troia nunca foi exatamente este tipo de mulher. Mas, no conjunto de poemas nos quais a sua imagem é menos preservada, um conjunto de obras que são tradicionalmente designadas por Ciclo Épico, e que apenas chegaram até nós através de resumos tardios ${ }^{7}$, temos um episódio revelador: depois da conquista de Troia, Menelau, de espada na mão, prepara-se para castigar Helena com a morte. No entanto, quando a vê, quando ela, em estudado gesto de súplica, lhe mostra o peito, imediatamente deixa cair a espada, de novo preso ao fascínio que sobre ele exerce aquela mulher. Uma coisa é derrotar milhares de troianos e os seus aliados, outra é enfrentar Helena.

Homero não se deixa enredar por estes efeitos melodramáticos, no sentido não grego do termo. ${ }^{8} 0$ que nos perturba nos poemas de Homero é a ambiguidade associada à figura de Helena9. E pode perturbar-nos ainda mais a primeira imagem que temos dela: no canto III da Ilíada, no primeiro momento em que vemos a esposa de Menelau, ela tece (Il. 3. 127-130). Ou seja, faz aquilo que qualquer mulher grega de elevado estatuto social faria normalmente. No entanto, e este é que é o ponto, os desenhos que vão surgindo na tapeçaria retratam os combates entre os Gregos e os Troianos. Por mais breve que seja o trecho - e ele é efetivamente muito breve - não deixa de ser impressionante o modo como Helena assume aqui uma dimensão demiúrgica, como nos é sugerido que, no enlear daqueles fios, pode estar a tecer-se o destino dos milhares de homens que combatem na planície em volta da cidade. É talvez uma das mais perfeitas formas de, em duas pinceladas, sugerir todo o poder desta mulher.

Ao longo da Ilíada, Helena aparece pouco e é particularmente poupada. É certo que, aqui e além, alguns guerreiros se lamentam por estarem envolvidos em combates tão longos e duros, tudo por causa de uma mulher. Mas aqueles que, no campo troiano, mais de perto com ela lidam parecem desculpá-la (são os deuses os culpados, sustenta Príamo, o velho rei de Troia) e respeitá-la. Em toda a Ilíada há apenas uma pessoa que diz coisas terríveis acerca de Helena. Essa pessoa é a própria Helena. É ela que repetidamente chama cadela a si própria, é ela que afirma que preferia ter morrido a estar ali, é ela que lamenta o 
abandono da casa de Menelau e da filha que deixou para trás. Com Páris a sua união é estéril, Homero faz questão de sublinhar que o que os move é o desejo, e isso afasta-se completamente da conceção grega do casamento que, de algum modo, apenas se poderia dizer efetivamente consumado após produzir descendência. Mais adiante, noutro momento breve mas extremamente significativo (Il. 3. 382-421), Helena discute com Afrodite, como se nela se desdobrassem, de forma eloquente, a mulher sensata e a chama que, nela, desperta o desejo dos homens. Mas o sofrimento de Helena, que não nos é dado distinguir até que ponto é real ou apenas aparente, não coloca fim à guerra e, enquanto Helena se lamenta e os corpos continuam a cair na planície, não conseguimos deixar de nos lembrar das mãos hábeis que, na quietude de uns aposentos luxuosos, continuam a desenhar a guerra e o seu destino.

Na Odisseia, ao aparecer no breve momento em que é visitada por Telémaco, na sua viagem em busca de Ulisses, Helena está de regresso à Lacedemónia, e a sua união com Menelau parece ter recuperado toda a harmonia. No entanto, a felicidade deste regresso ao lar não deixa de parecer pintada em papel de cenário, aliás vistoso, de tal forma a riqueza do palácio impressiona os dois jovens príncipes que o visitam. É algo como aquela sequência inicial do Blue Velvet, de David Lynch, de que alguns dos leitores eventualmente se lembrarão: à superfície, um relvado imaculadamente tratado, mas, se olharmos com atenção e mais fundo, a podridão alastra. Homero não vai tão longe, mas a harmonia ameaça esboroar-se quando, ao evocar Ulisses diante do filho, cada um dos anfitriões conta uma pequena história (Od. 4. 234-289). Helena relembra o episódio em que, correndo riscos, ajudou Ulisses que, disfarçado, se dirigira a Troia para espiar o inimigo; Menelau, por seu lado, recorda o momento em que, escondidos dentro do cavalo, os guerreiros veem as suas emoções desafiadas por Helena que, imitando as vozes das mulheres deles (como conseguiria ela fazer tal coisa?), chama pelos seus nomes enquanto anda em volta do cavalo de madeira. Quando um bom número deles está quase a quebrar, são travados pelo gesto decidido e ameaçador de Ulisses e a artimanha falha. Na justaposição destes dois relatos, tão evidentemente contraditórios, é a própria duplicidade de Helena que corrói uma harmonia de águas calmas apenas à superfície. Sempre ambíguo, Homero apenas espalha os 
sinais, deixa a nosso cargo se os valorizamos ou não. Já um pouco antes tinha deixado, novamente, algumas marcas da capacidade demiúrgica de Helena, quando ela, usando uma droga que trouxera do Egipto, fez com que os presentes ficassem isentos de sofrimento e de vontade de chorar, por mais dolorosas que fossem as recordações (Od. 4. 219-233). Este uso de um pharmakon - essa maravilhosa palavra, que tanto pode significar remédio como veneno - pertence também, na tradição grega, ao mundo feminino; mas, no caso de Helena, este espantoso remédio parece ter também qualquer coisa de sopro divino.

Se em Homero persiste uma estranha ambiguidade, o que vem a seguir também não deixa de causar estranheza. Helena é possivelmente a única figura da mitologia grega cuja história é alterada de forma radical, sofrendo uma completa reversão. 0 poeta Estesícoro, autor de longas composições corais de temática épica, terá composto uma palinódia de Helena, ou seja, um canto de retratação, ou, numa tradução ainda mais literal, um canto em sentido oposto (cf. Campbell 1991: 88-97). Nessa versão, Helena nunca teria viajado para Troia, em seu lugar teria ido uma imagem (um eidolon), em tudo semelhante a ela, que teria sido suficiente para enganar a todos. Se não temos o texto de Estesícoro, possuímos a Helena de Eurípides, que segue basicamente a mesma versão, mostrando-nos uma virtuosa Helena, refugiada no Egipto, ameaçada por um casamento que não quer, enquanto em Troia Gregos e Troianos combatem por uma imagem que a todos ilude (cf. Oliveira 2015). Esta versão, a que coloca milhares de homens a combater por uma imagem, uma figura de mulher que se esfuma no ar, em forma de nuvem, quando Menelau reencontra a verdadeira Helena, torna os longos anos da guerra de Troia uma empresa ridícula e mostra como Helena, ao ser substituída por uma imagem, pode ser reduzida a um invólucro, a uma aparência exterior. No Egipto, a verdadeira Helena vive dilacerada pela dicotomia $e u$ própria / o meu nome, a minha fama, obrigada a existir fora da narrativa mítica dominante, ao mesmo tempo que esta prossegue como se Helena lá estivesse de corpo inteiro. Por outro lado, Helena é transformada numa improvável Penélope, a quem Menelau, qual Ulisses, vem salvar de um pretendente feroz e ameaçador. E também como a Penélope de Homero, Helena brilha pela sua sensatez, e é ela quem engendra o plano que vai conduzir à salvação, diante da incapacidade de Menelau, sempre demasiado apagado e dependente. É 
este o paradoxo mais difícil de resolver: se, por um lado, Helena é reconduzida à função de boa e fiel esposa, e assim se integra no desenho feminino que fazia sentido no mundo grego, por outro a esposa de Menelau lidera e domina toda a cena, sublinhando assim a sua inegável diferença.

Como se compreende, reverter o mito de Helena coloca qualquer autor diante de um desafio extremo: como absolver Helena, como retirá-la de Troia, sem fazer desaparecer os dez anos de guerra? O eidolon parece uma hipótese interessante, ainda que demasiado fantástica: coloca os homens diante da sua fraqueza, instrumentos de maquinação divina que os ultrapassa e os leva a combater por uma ilusão. Mas a solução mais engenhosa e racional chega-nos pela voz do historiador Heródoto, nas suas Histórias (cf. II. 112-120). ${ }^{10} 0$ historiador afirma ter ouvido este relato a sacerdotes egípcios. Segundo ele, depois de raptar Helena, Páris foi obrigado a deixá-la no Egipto pelos soberanos daquele país, como castigo pelo ato que tinha praticado. Os Gregos, no entanto, partiram em perseguição de Páris e, chegados a Troia, exigiram a devolução de Helena. Os Troianos responderam que não a tinham, mas os Gregos não acreditaram, e por dez anos combateram, por mais que os Troianos jurassem que Helena não estava em Troia. Só depois de conquistarem a cidade é que os Gregos perceberam que os Troianos não mentiam. E o próprio Heródoto, muito racional, legitima esta versão: pois Príamo, rei de Troia, ao ver a cidade e os seus sob ameaça, ao ver os cadáveres a amontoar-se, alguma vez hesitaria um momento que fosse em devolver Helena, se a tivesse junto de si, por mais que Páris protestasse? Esta versão de Heródoto, a de que a guerra de Troia aconteceu porque, afinal, Helena nunca esteve em Troia, é absolutamente deliciosa, para além de imbatível em termos de lógica. E continua a ter como fundo esta noção terrível, a de que a mais cruel e destruidora das guerras se combateu em vão.

Depois de surgir, a versão que isenta Helena de responsabilidades nunca esteve sozinha e nunca foi maioritária. 0 mesmo Eurípides que nos deu Helena coloca esta figura, em várias das suas peças, retratada de acordo com o padrão tradicional. É o caso de $A s$ Troianas, peça na qual Helena tem um longo confronto verbal com Hécuba, que faz recair sobre a rainha da Esparta as mais terríveis acusações. Ou de Orestes, onde, numa pequena 
mas reveladora passagem, Helena, ao preparar-se para uma homenagem fúnebre, a realizar no túmulo de Agamémnon, corta ao de leve a ponta dos seus cabelos, apenas preocupada em manter a beleza do penteado, sem cuidar da importância simbólica da madeixa de cabelos que deveria ser colocada no túmulo. Ou seja, Helena não se livra do seu fardo, que é a sua fama e distintas Helenas vão desenhando o seu caminho, em vias paralelas que, mesmo não se tocando, apenas por existirem, ruidosamente comunicam.

As várias versões de um mito vão coexistindo e, distintas entre si, permitem-nos testar leituras e sensibilidades. É evidente que a Clitemnestra de Ésquilo é diferente da de Sófocles ou da de Eurípides, mas, no entanto, há qualquer coisa que as aproxima. Com Helena, a capacidade de as narrativas míticas se refazerem vai muito mais longe, ainda no período da antiga Grécia. Com versões tão distintas entre si, a desenvolverem-se em simultâneo, não fica claro se o efeito é desfocar Helena ou sublinhar nela uma complexidade que um primeiro olhar certamente não adivinharia. Nem sequer é seguro que o público grego ficasse mais apaziguado com a Helena fiel e dedicada, tanto ela simboliza, por um lado, a capacidade de as divindades jogarem aos dados com as vontades e as emoções dos pobres mortais, como, por outro, a própria Helena se revela, na versão de Eurípides, possuidora de um poder, de uma audácia, de uma voz de comando, hábil, mas segura, que seria certamente capaz de abalar alguns preconceitos masculinos.

Helena, a de Troia e a de Esparta, a esposa de Páris e a esposa de Menelau, a mulher que causou uma guerra ou aquela que nunca chegou a pôr os pés em Troia, constitui, ainda hoje, um exemplo particularmente perturbador. E dá-nos uma importante lição: convém não esquecer que, se os mitos gregos nos desafiam, isso acontece porque, antes de mais, começaram por desafiar-se a si próprios. ${ }^{11}$ 


\section{Bibliografia}

Austin, Norman (1994), Helen of Troy and Her Shameless Phantom, Iyhaca/London, Cornell University Press.

Bañuls, José Vicente et al. (2007), O mito de Helena de Tróia à actualidade, Coimbra, Universidades de Coimbra, Foggia, Granada e Valencia.

Blondell, Rubi (2013), Helen of Troy: Beauty, Myth, Devastation, Oxford, Oxford University Press.

Buxton, Richard (2000), El imaginario griego. Los contextos de la mitologia, trad. César Palma, Madrid, Cambridge University Press [1994, The imaginary Greece. The contexts of mythology, Cambridge, Cambridge University Press].

Campbell, David A. (1991), Greek Lyric. Stesichorus, Ibycus, Simonides, and others, Cambridge Mss, Harvard University Press.

Correia, Hélia (2000), Rancor. Exercício sobre Helena, Lisboa, Relógio d’Água.

Csapo, Eric (2005), Theories of Mythology, Malden/Oxford, Blackwell Publishers.

Detienne, Marcel (1992), L'invention de la mythologie, Paris, Gallimard [1981].

Fantuzzi, Marco / Christos Tzagalis (eds.) (2015), The Greek Epic Cycle and Its Ancient Reception. A Companion, Cambridge, Cambridge University Press.

Griffin, Jasper (2001), “The Epic Cycle and the Uniqueness of Homer”, in Cairns, Douglas L. ed., Oxford Readings in Homer's Iliad, Oxford, Oxford University Press: 365-384.

Gumpert, Matthew (2001), Grafting Helen: The Abduction of the Classical Past, Madison, The University of Wisconsin Press.

Hughes, Bethany (2008), Helena de Troia. Deusa, Princesa, Prostituta, trad. Maria José Santos, Lisboa, Aletheia [2005].

Jabouille, Víctor (1993), Do mythos ao mito. Uma introdução à problemática da mitologia, 
Jorge Deserto

\section{Lisboa, Cosmos.}

Jabouille, Víctor (1994), Introdução à ciência dos mitos, Mem Martins, Inquérito [2ª ed.].

Lourenço, Frederico (2014a), Homero. Ilíada, Lisboa, Livros Cotovia [2 ${ }^{\mathrm{a}}$ ed.]

Lourenço, Frederico (2014b), Homero. Odisseia, Lisboa, Livros Cotovia [2 $2^{\mathrm{a}}$ ed.].

Maguire, Laurie (2009), Helen of Troy: From Homer to Hollywood, Malden/Oxford, Blackwell Publishers.

Meagher, Robert E. (1995), The Meaning of Helen. In Search of an Ancient Icon, Wauconda (Il.), Bolchazy-Carducci Publishers.

Mendonça, José Tolentino (2005), Perdoar Helena, Lisboa, Assírio \& Alvim.

Miranda, Paulo José (1998), O corpo de Helena, Lisboa, Livros Cotovia.

Oliveira, Alessandra C.J.N. (2015), Eurípides. Helena, Coimbra, Imprensa da Universidade de Coimbra.

Pomeroy, Sarah B. (1975), Goddesses, Whores, Wifes and Slaves. Women in Classical Antiquity, New York, Schocken Books.

Powell, Barry B. (2002), A Short Introduction to Classical Myth, Upper Sadle River (NJ), Prentice Hall.

Suzuki, Mihoko (1989), Metamorphoses of Helen. Authority, Difference, and the Epic, Ithaca/London, Cornell University Press.

Taplin, Oliver (ed.) (2000), Literature in the Greek World, Oxford, Oxford University Press.

Vernant, Jean-Pierre (1965), Mythe et pensée chez les Grecs, Paris, Maspero.

West, Martin L. (2003), Greek Epic Fragments, Cambridge Mss., Harvard University Press.

West, Martin L. (2013), The Epic Cycle. A Commentaryon the Lost Troy Epics, Oxford, Oxford University Press.

Wilson, N.G. (2015), Herodoti Historiae. Libri I-IV, Oxford, Oxford University Press. 
Jorge Deserto é Professor Auxiliar na Faculdade de Letras da Universidade do Porto e investigador do Centro de Estudos Clássicos e Humanísticos da Universidade de Coimbra. Tem realizado investigação essencialmente nas áreas da literatura grega (com especial destaque para o teatro, tanto tragédia como comédia), da retórica, da receção das obras da antiguidade clássica, da obra do geógrafo Estrabão, de que traduziu, em coautoria, o livro III, dedicado à Ibéria (a publicar no decurso de 2016).

\section{NOTAS}

1 Sobre esta questão da presença dos mitos na infância e do papel das mães e das amas, veja-se Buxton 2000: 31-38.

${ }^{2}$ Cf. Burkert 1991: 15-20. Veja-se igualmente a criteriosa delimitação apresentada por Jabouille 1994: 36 -37.

3 Para uma abordagem da literatura grega que tem em especial atenção as condições de apresentação e de receção pública das obras literárias, vejam-se os estudos reunidos em Taplin 2000.

${ }^{4}$ Um dos exemplos recentes, e inesperados, desse diálogo é o filme de Spike Lee, Chi-raq, que transporta a Lisístrata de Aristófanes para o ambiente das lutas de gangs em Chicago. 0 filme estreou em dezembro de 2015 nos Estados Unidos e teve apresentação europeia no Festival de Cinema de Berlim, em fevereiro de 2016. É certo que uma intriga como a Lisístrata talvez não caiba por inteiro naquilo a que, com preocupações de pureza, chamamos mitologia grega, mas o processo de leitura, apropriação e reinvenção é certamente semelhante, até porque a passagem do tempo já juntou esta intriga, sem distinção, às outras que constituem o património da literatura grega. É, além disso, um dos mais conhecidos exemplos, no contexto grego, de uma figura feminina que claramente desafia e ultrapassa o estatuto social atribuído à mulher. Se, quando falamos 
da capacidade de renovação e da plasticidade destas narrativas, podemos encontrar Aristófanes nas mãos de Spike Lee, eis uma daquelas demonstrações que, por si mesma, dispensa argumentos adicionais.

5 É revelador do conjunto de papeis atribuídos às mulheres o título de uma das obras inaugurais de um conjunto vasto de estudos que têm vindo a ser dedicados à condição e ao estatuto da mulher grega: Goddesses, Whores, Wifes and Slaves. (Cf. Pomeroy 1975).

${ }^{6}$ Como se compreende é muito larga a bibliografia sobre Helena. Sem qualquer preocupação de esgotar o tema, poderão ser úteis os trabalhos de Suzuki (1989), Austin (1994), Meagher (1995), Gumpert (2001), Bañuls et al. (2007), Hughes (2008), Maguire (2009) ou Blondell (2013).

7 Os poemas do chamado Ciclo Épico constituiriam um conjunto de narrativas épicas, claramente menos depuradas do que a Ilíada ou a Odisseia, de datação incerta, mas não muito distantes no tempo das obras atribuídas a Homero. $\mathrm{O}$ conjunto de poemas do Ciclo Épico dedicados à guerra de Troia apenas chegou até nós em escassíssimos fragmentos e, além disso, através dos resumos de Proclo, um gramático do século II d.C., o que nos deixa uma imagem claramente insuficiente destas obras. 0 episódio aqui evocado é do poema designado como Pequena Ilíada (Ilias Mikra). Para um breve e acessível comentário, acompanhado de tradução, veja-se Davies 2001. Os fragmentos estão disponíveis em West 2003 e 2013, no primeiro caso com tradução, no segundo com o mais extenso comentário publicado até hoje. Veja-se, ainda, sobre a influência destas obras perdidas no tempo na literatura da Antiguidade, Fantuzzi/Tzagalis 2015.

${ }^{8}$ Claro e relevante contraste entre os poemas do Ciclo Épico e Ilíada e Odisseia é desenvolvido por Jasper Griffin (2001).

${ }_{9}^{9}$ Para a Ilíada e a Odisseia, vejam-se as excelentes traduções de Frederico Lourenço (2014a e 2014b).

${ }^{10}$ Para o texto de Heródoto, veja-se Wilson 2015. Não há, infelizmente, uma boa tradução deste segundo livro do historiador grego para português.

${ }^{11}$ Que o desafio continua, provam-no, sem sair do universo português, obras como $O$ corpo de Helena, de Paulo José Miranda (1998), Rancor, de Hélia Correia (2000) ou Perdoar Helena, de José Tolentino Mendonça (2005). 